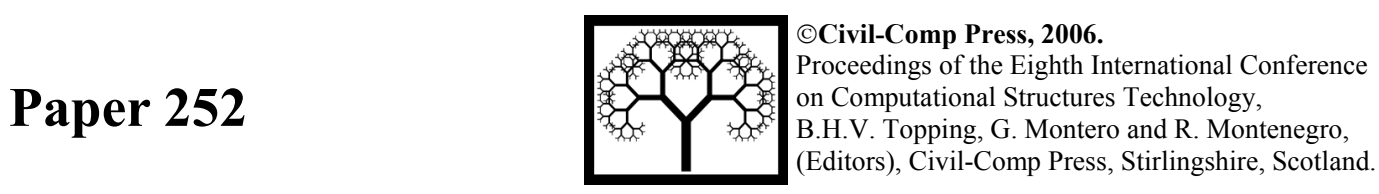

\title{
Seismic Behaviour of an Asymmetric Three-Dimensional Steel Frame with Base Isolation Devices
}

\author{
R.C. Barros† and M.B. César: \\ $\uparrow$ Department of Civil Engineering, Faculty of Engineering (FEUP) \\ University of Porto, Portugal \\ + Polytechnic Institute of Bragança, Portugal
}

\begin{abstract}
A parametric study on the use of base isolation devices in frame building structures is undertaken. Frames were analysed with regular geometry starting from a baseframe (BF), from which more complex frames were created by association of BF in height above a certain asymmetric plant. The modularity of the BF facilitates the analysis of the results, allowing for parametric studies on the use of base isolation devices in more complex geometries. To conduct the computational studies the commercial software SAP2000 was used. Three-dimensional (3D) structures were analyzed with asymmetries in plant and in elevation. Some of the results of the parametric study are presented graphically, identifying the importance of positioning the seismic isolation devices used in each structural configuration.
\end{abstract}

Keywords: seismic behaviour, base isolation devices, asymmetric 3D metallic frames, parametric studies.

\section{Introduction}

The use of energy dissipation devices in structures should be carefully studied in order to optimise location increase efficiency and obviously to decrease the costs of its application. For long span or tall structures (namely continuous beams, tall buildings and suspended or tied bridges) these approaches are fully justified; also for general building structures, the geometric complexity makes it necessary to do parametric studies on the use of such devices, in order to hinder the best solution for each structural geometry or typology (Barros and Cesar [1]).

In this study is analysed the behaviour of structures under seismic actions, equipped with energy dissipation devices; more concretely, support devices of the type "Base Isolation" (BI) to lessen the effects of the dynamic seismic actions in the structural systems (Figure 1). 

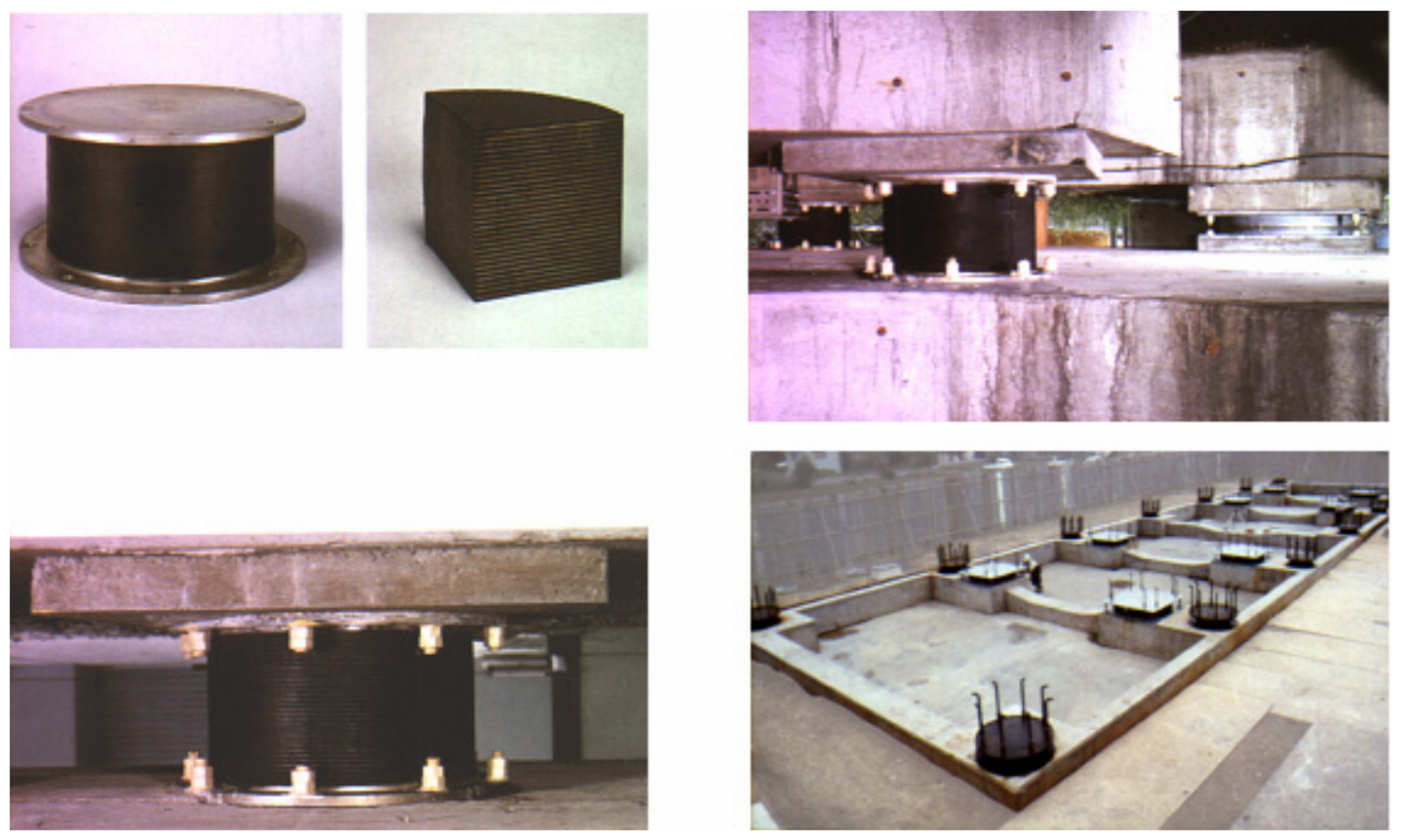

Figure 1: Seismic isolators and some of their real applications

This study is more and more important not only in the great building enterprises or in high-risk tall buildings, which justify the use of dissipation devices for their social-economic importance, but also in the average constructions since the application of dissipation and isolation devices is economically viable.

To opt for a dissipation system, among the possible BI devices, it is quite convenient to know the best constructive solution in order to minimize costs, as well as to analyze the possibility of its use in existing constructions whose seismic retrofit is required to assure an adequate resistant capacity and performance under service conditions.

The occurrence in Portugal of a great magnitude earthquake is probable, above all in the high-risk seismic zone A, according to the Regulamento de Segurança e Acções para Estruturas de Edificios e Pontes (RSA [2]). Addressing this parametric study on the use of seismic isolation devices in frame buildings in Portugal is very important, at least under the viewpoints of the preparedness of the structures to support strong seismic actions, as well as of the retrofit of damaged or susceptible important buildings or lifeline infrastructures.

In this context was chosen a 3D steel building frame seismically isolated, with asymmetric plan but also with the possibility of distinct structural configurations in elevation, for the purpose of understanding the role and influence of some geometric parameters on the performance of the frame under seismic actions. Such asymmetric 3D building frame was already used extensively by the authors in a completely different study, related to the carrying capacity and overall stability characteristics of the frame (Barros and Cesar [3]) (Cesar [4]) (Cesar and Barros [5] [6]). Most of the computational analysis required by the parametric study was performed using the commercial software SAP 2000 [7]. 
Firstly the 3D metallic frame was pre-designed in agreement with the Portuguese standards and regulations, namely RSA [2]. This pre-design is achieved for several parametric variations of the geometry of the structure. Thereafter an energy dissipation system of base isolation devices is devised, whose characteristics are introduced in SAP 2000 in order to develop a parametric study of the behaviour of the frame under seismic actions.

\section{Structural Modelling}

\subsection{General aspects}

The energy dissipation devices correspond to support apparels constituted by rubber sheets inserted with foils of steel that are united by vulcanization.

To achieve a calibration process of the considered metallic steel 3D frames seismically isolated at the base of each column, such calibration frames were modelled using frame bar elements considering rigid connections between the beams and the columns.

The structures were analyzed for two parametric variations - variation of the lengths of the structural elements (controlling frame spans and inter-story heights) and variation of the number of rigid slabs (asymmetry in elevation) - for each of which were determined the natural frequencies and the vibration mode shapes.

For a frame structural model (Figure 2) with 1 translational degree of freedom (DOF) - where $\mathrm{m}$ represents the mass, $k$ the stiffness of the columns and $c$ the damping coefficient - the displacement on the top of the frame is denoted by $u(t)$ and the one of the base by $u_{g}(t)$.

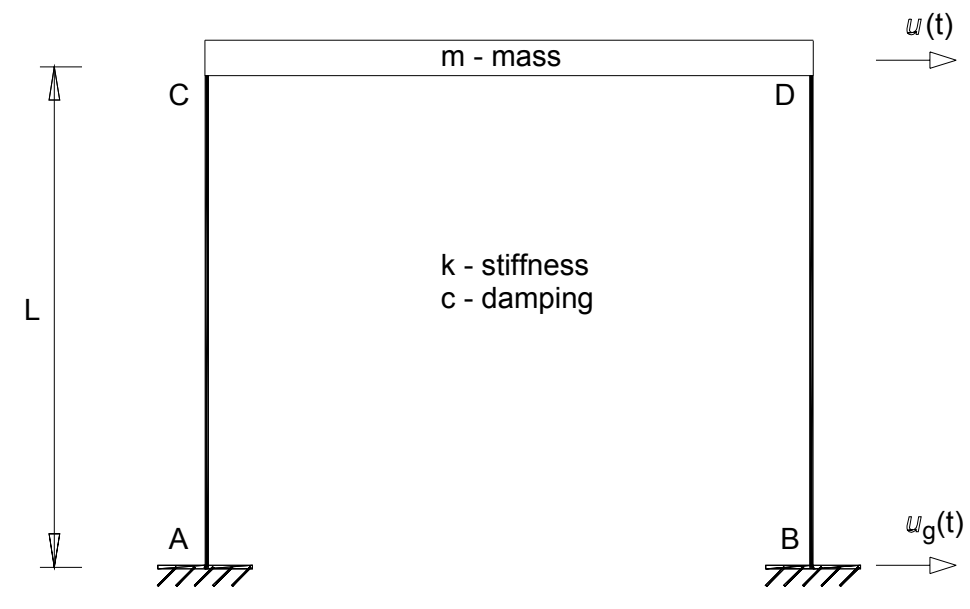

Figure 2: 1-DOF frame and conventions

The equation of motion, in global coordinates, is given by:

$$
m \ddot{u}+c\left(\dot{u}-\dot{u}_{g}\right)+k\left(u-u_{g}\right)=0
$$

Dividing equation (1) by $m$, the following equation is obtained 


$$
\ddot{u}+2 \omega \zeta \dot{u}+\omega^{2} u=-\ddot{u}_{g}
$$

in which $\omega$ is the angular (circular) undamped natural frequency of the structure and $\zeta$ is the damping factor (as a percentage of critical damping coefficient).

For a frame structural model with $\mathrm{N}$ translational DOF, equation (1) is substituted by the matrix equation

$$
M \ddot{u}+C \dot{u}+K u=-M r \ddot{u}_{g}
$$

in which $M$ is the mass matrix of the structural system, $C$ the damping matrix, $K$ is the stiffness matrix, $u$ is the vector of displacements (relative to the base) and $r$ the vector that associates the displacements of the base to the translational degrees of freedom.

The solution of this equation (3) departs from the characteristic equation (4), from which are determined the angular undamped frequencies $\omega$ and the associated vibration modes $\phi$.

$$
\operatorname{det}\left(-\omega^{2} M+K\right)=0
$$

\subsection{Calculation model}

The first approach in the analysis of structures with energy dissipation devices at the base (ie, Base Isolation) is based on the use of a model with 2 (translational) DOF, represented in Figure 3: one DOF at the level of the base isolators; the $2^{\text {nd }}$ DOF at the floor level. The background to this work was based on Naeim and Kelly [8] that resumes the state-of-the-art of seismic isolation and the design of seismic isolated structures, within the framework of existing codes - as well on Soong and Dargush [9].

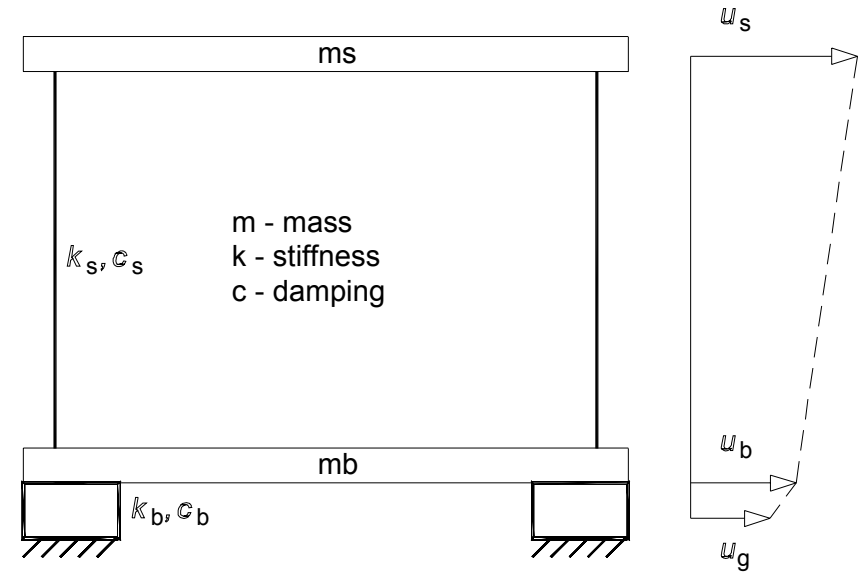

Figure 3: One-floor based isolated frame

In this outline the most important factor is the capacity of energy absorption, using a dissipation model based on the linear viscous damping behaviour of the base isolation devices. 
One of the difficulties is related with the selection of the real modal damping factors (Alhan and Gavin [10]) (Osinski, [11]). The use of BI devices permits to reduce the forces supported by the structure, up to values for which do not occur significant structural and/or frame members damages (as well as in non-structural partition walls).

A system of base isolation devices made of natural rubber guarantees a degree of damping in the order of $10-20 \%$ of the critical damping, considerably bigger than structural damping factors for steel frames (in the order of $2 \%$ ). Usually, in conventional structural analysis, a structural damping factor of 5\% (of the critical damping) is used admitting the possibility of structural damages occurrence during a large intense earthquake.

When the behaviour of a base-isolated multi-DOF steel frame is considered (Figure 4) it is important to evaluate the "drift" and the maximum acceleration in the most unfavourable locations. Comparing the values calculated for the frames, with and without BI, some degree of efficiency of the BI devices can be achieved, since they reduce vibration seismic effects in function of their placement and of the geometry properties of the structure.

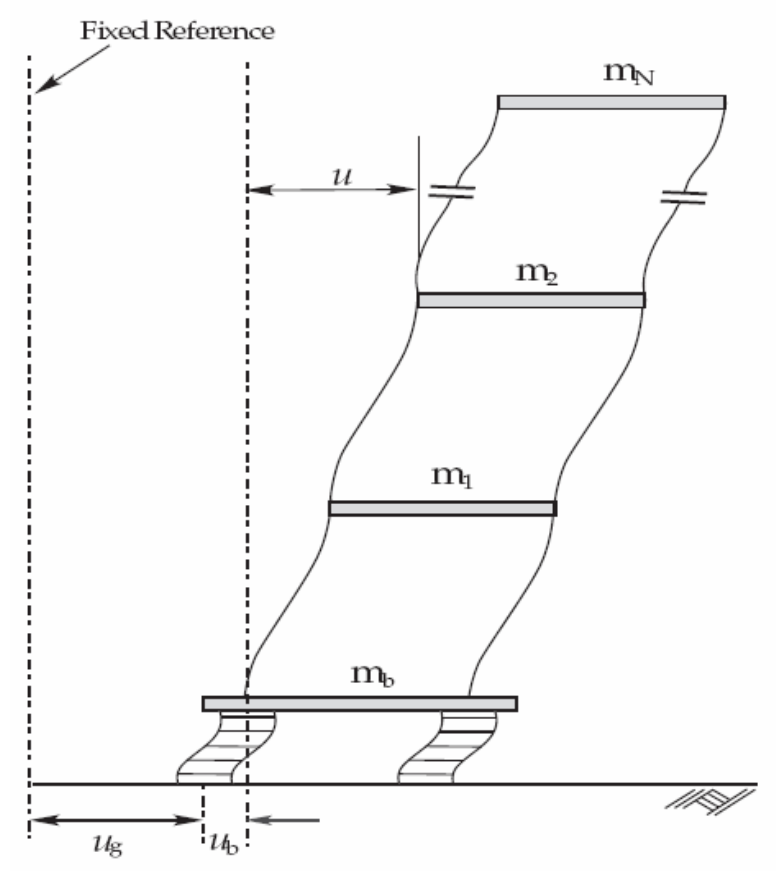

Figure 4: Behaviour of a base-isolated frame with several floors (MDOF)

Normalization codes and regulations, namely the pre-norm pr EN 1337 (CEN [12]), define several types of base isolation devices (or isolators) as illustrated in Figure 5. In this work were followed the recommendations of SETRA [13]. The characteristics of the elastomer used in the BI devices were determined in laboratory tests; they allow defining maximum design values for shear strain as a function of the rupture shear strain between the elastomer and the composite sandwich device (Table 1). 


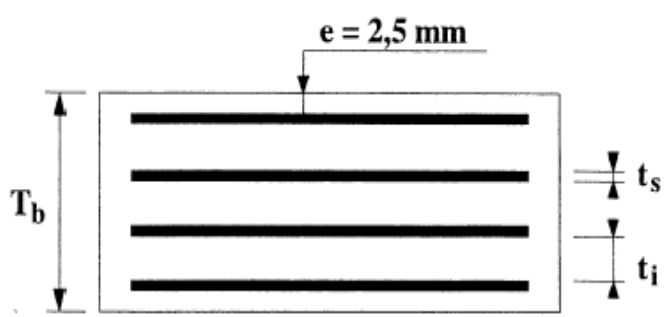

$\mathrm{T}_{\mathrm{b}}=3\left(\mathrm{t}_{\mathrm{i}}+\mathrm{t}_{\mathrm{s}}\right)+\mathrm{t}_{\mathrm{s}}+5 \mathrm{~mm}$

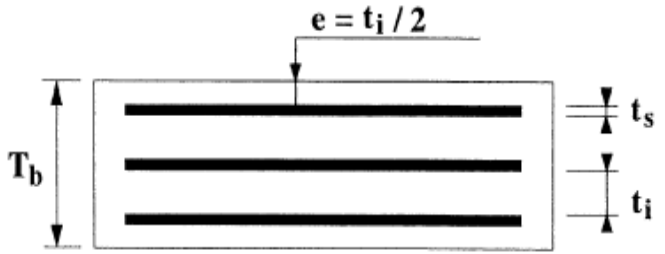

$\mathrm{T}_{\mathrm{b}}=3\left(\mathrm{t}_{\mathrm{i}}+\mathrm{t}_{\mathrm{s}}\right)$

Figure 5: Characteristics of the BI devices

\begin{tabular}{|c|c|}
\hline $\begin{array}{c}\text { Maximum strain for } \\
\text { shear design }(\tan \gamma)\end{array}$ & $\begin{array}{c}\text { Rupture experimental strain } \\
\text { of the elastomer at the } \\
\text { composite device }(\tan \gamma)\end{array}$ \\
\hline 1.4 & 2.0 \\
\hline 1.6 & 2.25 \\
\hline 1.8 & 2.5 \\
\hline 2.0 & 2.75 \\
\hline
\end{tabular}

Table 1: Design shear strain vs Rupture shear strain (for devices used in Europe)

One of the main characteristics that define the behavior of the elastomer isolator is the lateral rigidity of the $\mathrm{BI}$ device, given by the equation

$$
K_{h}=\frac{G \cdot A}{t_{r}}
$$

in which $G$ is the shear modulus, $A$ the area of the elastomer and $t_{r}$ the thickness of the several rubber layers. SETRA [13] technical guide indicates the values to be adopted in the design of $\mathrm{BI}$ devices that equip civil engineering works of art. In this case a shear modulus $\mathrm{G}=900 \mathrm{kPa}$ is used for design of structures subjected to slow actions, and $\mathrm{G}=1200 \mathrm{kPa}$ for design of structures subjected to fast actions (like an earthquake). On the base of such characteristic, the maximum allowed distortion $v_{x}$ is determined, and the BI device is selected guaranteeing that the acceptable maximum distortion values are not surpassed.

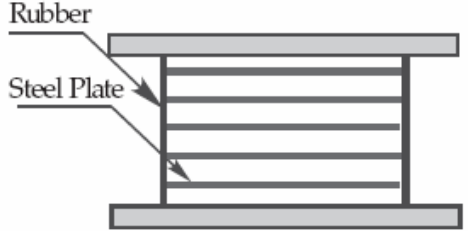

Elastomeric Bearing

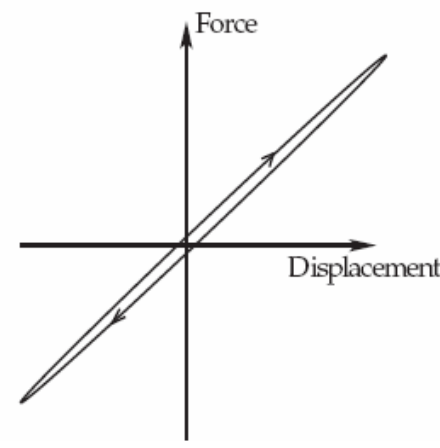

Figure 6: Behaviour of an elastomer isolator 


\subsection{Dynamic earthquake actions}

In this study the earthquake response spectra presented in design code RSA [2] were used, for two types of earthquakes and three types of foundation soils, each of which with curves for damping factors of $2 \%, 5 \%$ and $10 \%$. Such design spectra (some of which are shown in Figures 7 and 8, for 3 damping factors) were introduced in the calculation software SAP 2000 [7], for determining structural responses under the most unfavorable combination of actions.

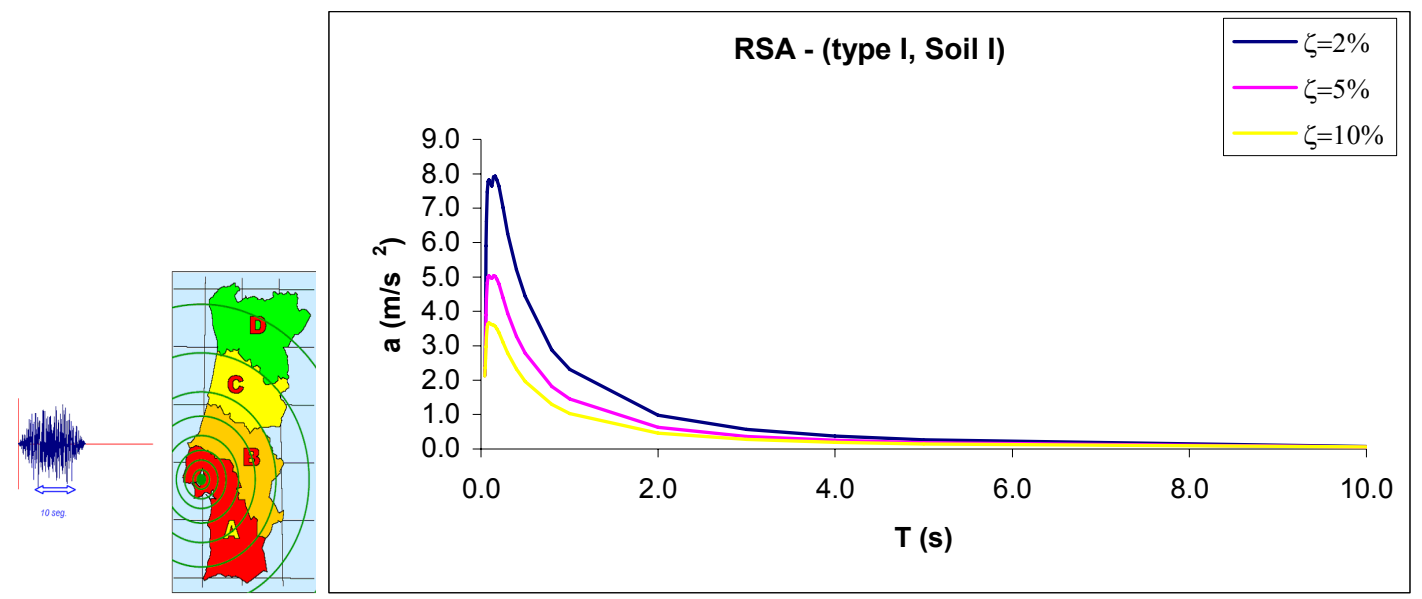

Figure 7: Response spectra (of RSA) for earthquake-type 1 and soil-type 1

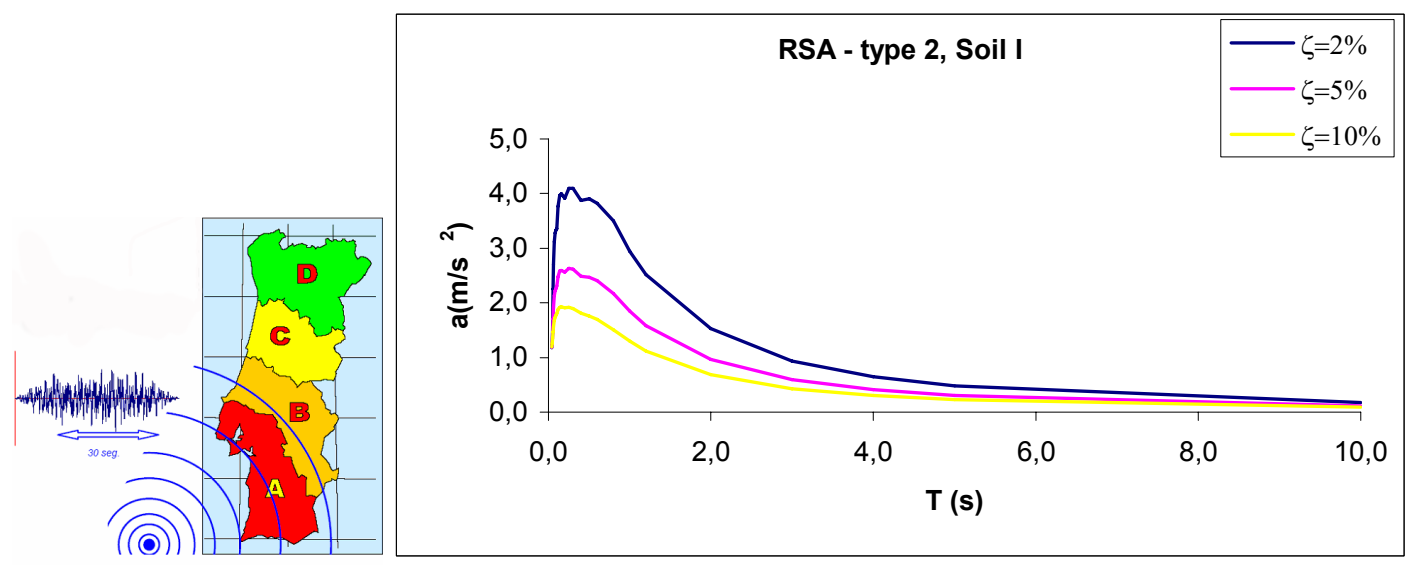

Figure 8: Response spectra (of RSA) for earthquake-type 2 and soil-type 1

The asymmetric base-isolated 3D steel frame used in this study, is considered founded in soil-type 1 (hard soil) in the most vulnerable seismic zone - Zone A (for which the seismic coefficient, for structural usage, equals unity). Also, for the asymmetric structures of this parametric analysis, the response spectrum for the intermediate damping factor of $5 \%$ is used. 


\section{Parametric Study}

\subsection{General characteristics}

After some needed acquaintance with the commercial software SAP 2000 [7] with a standard calibration analysis to understand its characteristics and inherent potential, several parametric studies on 3D base-isolated steel frames were elaborated after introducing the required variables defining the elastomer isolators of the BI devices.

Although in the initial study several structural systems have been modelled, in the present parametric study (Barros and Cesar [1]) only will be presented a summary of the results associated with the seismic analysis of an asymmetric baseisolated 3D steel frame with 5 floors (but also with asymmetry in elevation besides the asymmetry in plant) already used by the authors (Barros and Cesar [3]) (Cesar [4]) (Cesar and Barros [5] [6]) for characterizing the carrying capacity and the stability properties of the same asymmetric 3D frame (Figures 9 and 10).

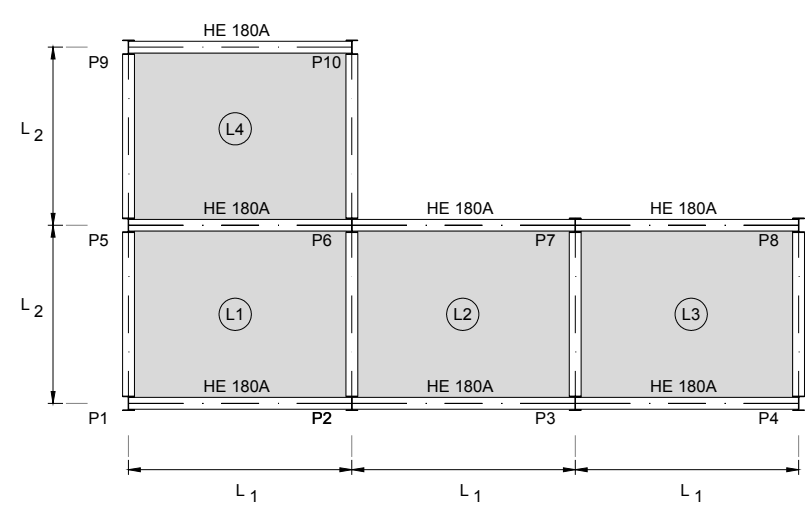

Figure 9: 3D frame with asymmetry in plant (designation of the beams, columns, frames and slabs)

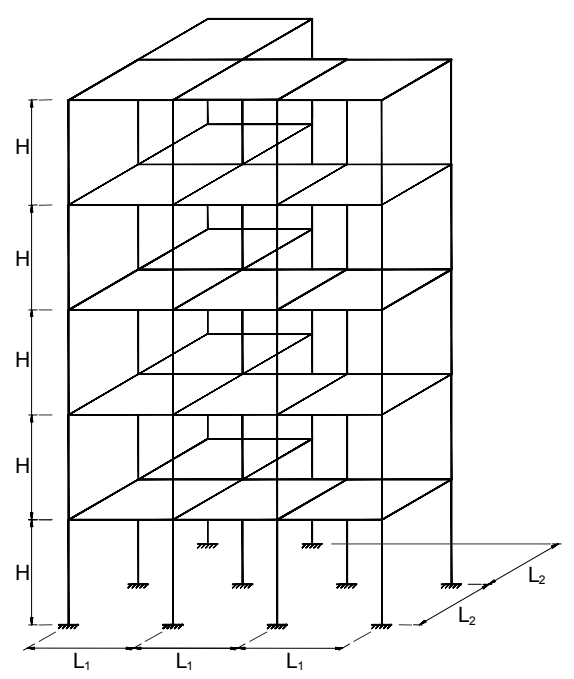

Perspective

\begin{tabular}{|c|c|c|c|c|c|}
\cline { 2 - 6 } \multicolumn{1}{c|}{} & $\begin{array}{c}\text { Floor } \\
\mathbf{1}\end{array}$ & $\begin{array}{c}\text { Floor } \\
\mathbf{2}\end{array}$ & $\begin{array}{c}\text { Floor } \\
\mathbf{3}\end{array}$ & $\begin{array}{c}\text { Floor } \\
\mathbf{4}\end{array}$ & $\begin{array}{c}\text { Floor } \\
\mathbf{5}\end{array}$ \\
\hline P1 & $200 \mathrm{~A}$ & $200 \mathrm{~A}$ & $180 \mathrm{~A}$ & $180 \mathrm{~A}$ & $160 \mathrm{~A}$ \\
\hline P2 & $220 \mathrm{~A}$ & $220 \mathrm{~A}$ & $200 \mathrm{~A}$ & $180 \mathrm{~A}$ & $140 \mathrm{~A}$ \\
\hline P3 & $220 \mathrm{~A}$ & $220 \mathrm{~A}$ & $200 \mathrm{~A}$ & $180 \mathrm{~A}$ & $140 \mathrm{~A}$ \\
\hline P4 & $200 \mathrm{~A}$ & $200 \mathrm{~A}$ & $180 \mathrm{~A}$ & $180 \mathrm{~A}$ & $160 \mathrm{~A}$ \\
\hline P5 & $220 \mathrm{~A}$ & $220 \mathrm{~A}$ & $200 \mathrm{~A}$ & $180 \mathrm{~A}$ & $140 \mathrm{~A}$ \\
\hline P6 & $240 \mathrm{~A}$ & $220 \mathrm{~A}$ & $200 \mathrm{~A}$ & $180 \mathrm{~A}$ & $140 \mathrm{~A}$ \\
\hline P7 & $220 \mathrm{~A}$ & $220 \mathrm{~A}$ & $200 \mathrm{~A}$ & $180 \mathrm{~A}$ & $140 \mathrm{~A}$ \\
\hline P8 & $200 \mathrm{~A}$ & $200 \mathrm{~A}$ & $180 \mathrm{~A}$ & $180 \mathrm{~A}$ & $160 \mathrm{~A}$ \\
\hline P9 & $200 \mathrm{~A}$ & $200 \mathrm{~A}$ & $180 \mathrm{~A}$ & $180 \mathrm{~A}$ & $160 \mathrm{~A}$ \\
\hline P10 & $200 \mathrm{~A}$ & $200 \mathrm{~A}$ & $180 \mathrm{~A}$ & $180 \mathrm{~A}$ & $160 \mathrm{~A}$ \\
\hline \multicolumn{5}{|c|}{ Profiles of the columns (designations) }
\end{tabular}

Figure 10: Elevation of the 3D asymmetric frame (perspective, column properties) 
The parametric analysis is based upon the variation of the structural elements lengths (beam spans or distances between the columns L, and inter-story heights between floors $\mathrm{H}$ ) and in the definition of the space geometry (typology) of the asymmetric 3D structure (asymmetry in plan view as represented in Figure 9; asymmetry in elevation, as represented in Figure 11, based on location of the slabs L2 and L3 respectively up to $5^{\text {th }} 4^{\text {th }}$ or $3^{\text {rd }}$ floors).
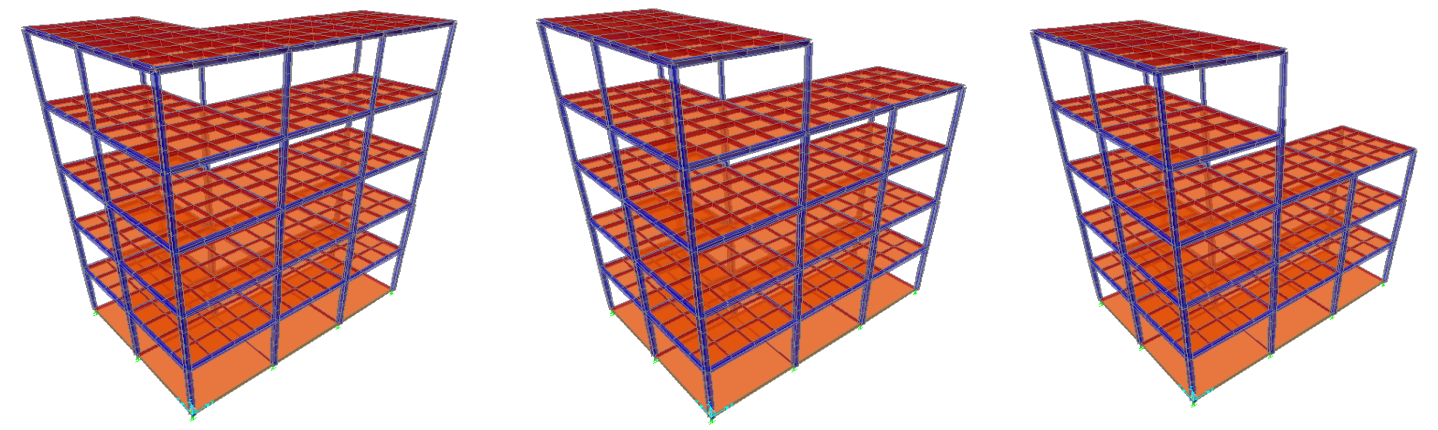

Figure 11: 3D base-isolated steel frame (with asymmetries in plan and in elevation)

\subsection{Parametric variation and results}

In the network report of Barros and Cesar [1], three different values were considered for the beam spans or distances between the columns ( $\mathrm{L}: 4.0 \mathrm{~m}, 6.0 \mathrm{~m}$ and $8.0 \mathrm{~m}$ ) and two inter-story heights between floors $(\mathrm{H}: 3.0 \mathrm{~m}$ and $4.0 \mathrm{~m})$.

Initially, for a set of geometric-typological properties (L, H, typology) and for the 3D asymmetric frame modeled without elastomer isolators at the base of the columns, the acceleration and the lateral displacement of a top-floor node (node 57 in the 3D frame modeling) were determined. Later on, with the same geometrictypological properties but now with elastomer isolators at the base of the columns, the 3D asymmetric frame was re-analyzed for the evaluation of the same displacement control variables. This was continuously repeated for the universe of the geometric-typological combinations, and the corresponding results are shown herein in graph form.

The elastomer isolators, applied at the bottom of each column to reduce the effects of the seismic actions, were pre-designed according to SETRA [13] for the maximum vertical loads at the ultimate limit state (ULS); nevertheless the performance of the BI device should be verified for the serviceability limit state (SLS). A circular isolator was selected with the following characteristics: $G=1200$ $\mathrm{kPa}$ (fast earthquake actions) and $\varnothing=550 \mathrm{~mm}$, to which correspond a horizontal stiffness of $1000 \mathrm{kN} / \mathrm{m}$; a damping factor of $5 \%$ was considered. Through the comparison of the values attained by the same displacement control variables (acceleration and lateral displacement of a top-floor node 57 in the 3D frame modelling), the performance role and behaviour (and somehow the efficiency) of the elastomer isolators were verified. The location of the reference node 57 is represented in Figure 12, chosen along a column elevation from $1^{\text {st }}$ to $5^{\text {th }}$ floor that did not change in the parametric study. 


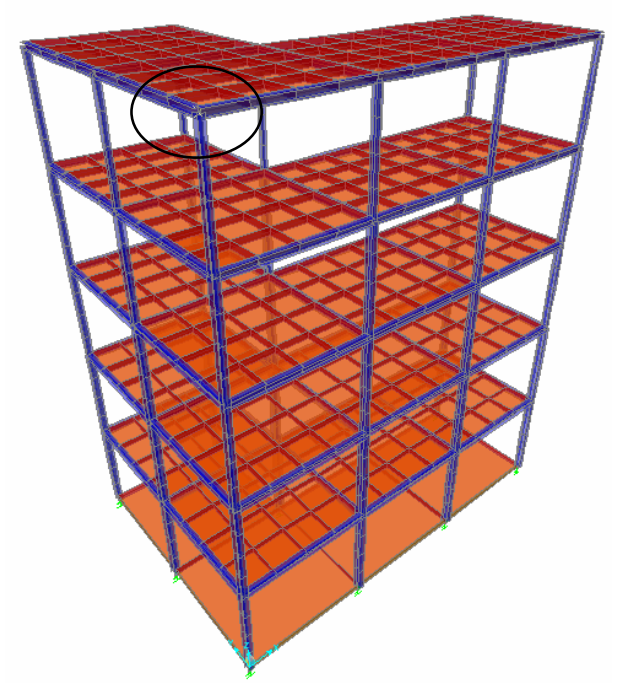

Figure 12: Location of reference node 57 in the 3D asymmetric frame

A linear modal analysis was accomplished. The response spectra of Figures 7 and 8 were used simultaneously in the two horizontal directions, for modal damping factors of $5 \%$.

On the base of the obtained results, the following graphs (Figures 13-14-15-16) were elaborated for the resultant total acceleration (from $a_{x}$ and $a_{y}$ ) and for the resultant relative displacement (from $\mathrm{x}$ and $\mathrm{y}$ relative displacements) occurring at reference node 57 (of Figure 12) for the same inter-story height $\mathrm{H}=3 \mathrm{~m}$ and for 3 values of the beams spans $(\mathrm{L}=4,6,8 \mathrm{~m})$.

Figure 13 refers to the resultant total acceleration for the asymmetric frame without base-isolation devices; Figure 14 refers to the resultant total acceleration for the asymmetric frame with base-isolation devices.

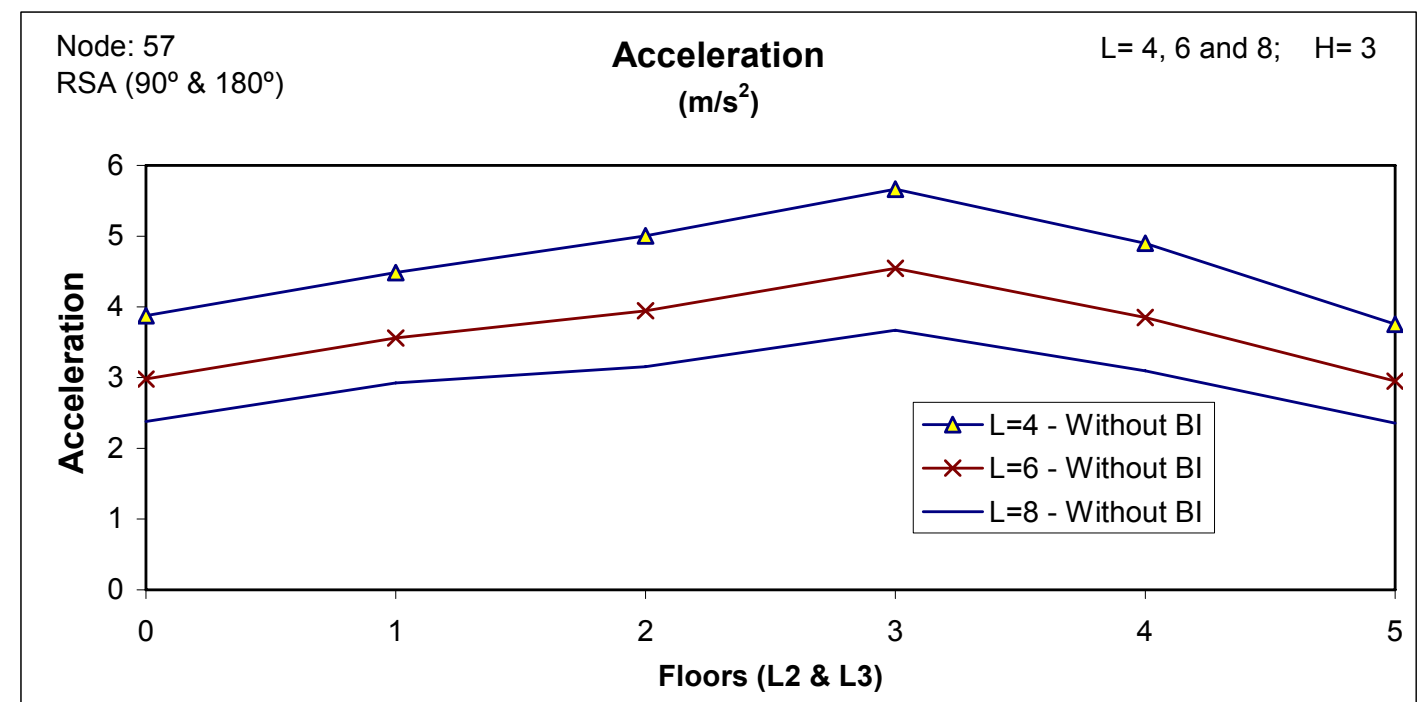

Figure 13: Resultant total acceleration for asymmetric frame without base-isolation devices $(\mathrm{H}=3 \mathrm{~m}$; parametric study for $\mathrm{L}=4,6$ and $8 \mathrm{~m})$ 


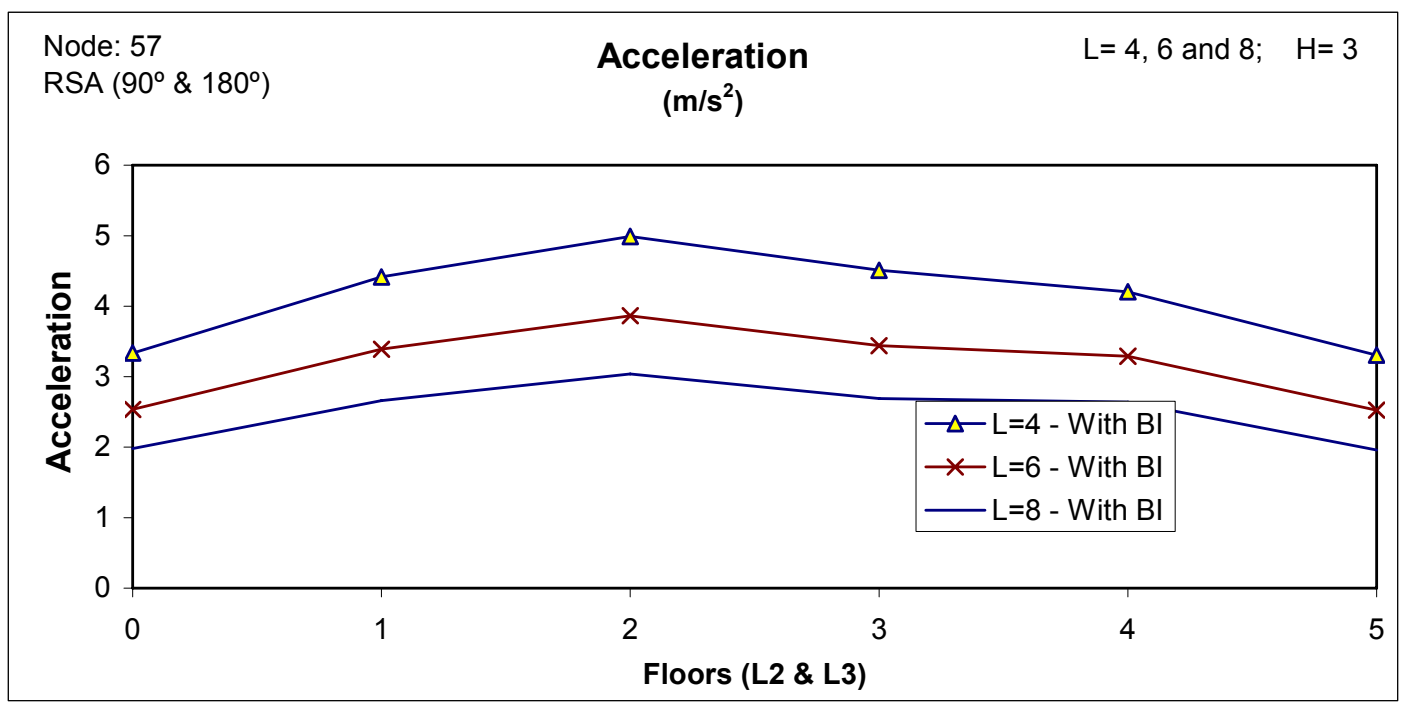

Figure 14: Resultant total acceleration for asymmetric frame with base-isolation devices $(\mathrm{H}=3 \mathrm{~m}$; parametric study for $\mathrm{L}=4,6$ and $8 \mathrm{~m})$

It is verified that the evolution of the curves is proportional presenting an increase of the total acceleration with the decrease of the beam spans or distance between columns (L). The maximum total acceleration, for the $3 \mathrm{D}$ frame without $\mathrm{BI}$ devices, is obtained for the use of 3 rigid floors L2 and L3; the maximum acceleration, for the 3D frame with $\mathrm{BI}$ devices, is obtained for the use of 2 rigid floors L2 and L3.

From the values obtained in the parametric study it is verified that the behaviour of the asymmetric 3D frame is altered when exist 1 to 5 floors of the rigid slabs L2 and L3; the most favourable effect (maximum decrease of total acceleration) associated with the use of BI devices happens when 3 rigid slab floors exist, for which occurs the larger difference between the resultant total acceleration without and with elastomer isolators. When only 1 and 2 floors exist of the rigid slabs L2 and L3 the use of BI devices changes the frame acceleration response, but such changes are not so significant as when the other floors also exist; this is due to the flexibility of the upper $3^{\text {rd }} 4^{\text {th }}$ and $5^{\text {th }}$ floors that control the behaviour of the $3 \mathrm{D}$ frame. So, BI is more important for high-rise tall buildings than for low-rise buildings.

Figure 15 refers to the resultant relative displacement for the asymmetric frame without base-isolation devices; Figure 16 refers to the resultant relative displacement for the asymmetric frame with base-isolation devices.

As can be observed, the resultant relative displacement stays practically constant for corresponding cases of the parametric study, without and with BI devices, with respect to the number of rigid slab floors used (slabs L2 and L3). For the asymmetric frame without BI devices, is noticed a slight increase in relative displacements of the reference node up to the use of 3 rigid slab floors (slabs L2 and L3).

The difference between relative displacements stays practically constant for corresponding cases of the parametric study, without and with BI devices, with respect to the number of rigid slab floors used (slabs L2 and L3). 


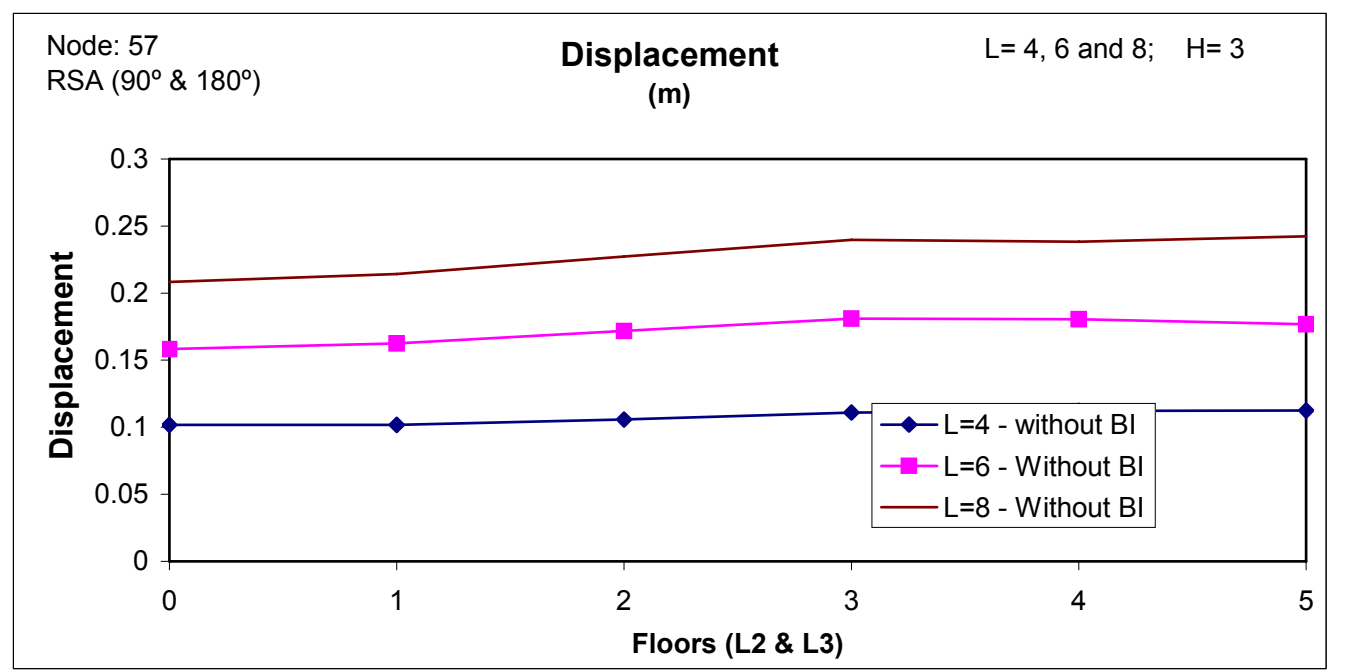

Figure 15: Resultant relative displacement for asymmetric frame without BI devices

$(\mathrm{H}=3 \mathrm{~m}$; parametric study for $\mathrm{L}=4,6$ and $8 \mathrm{~m})$

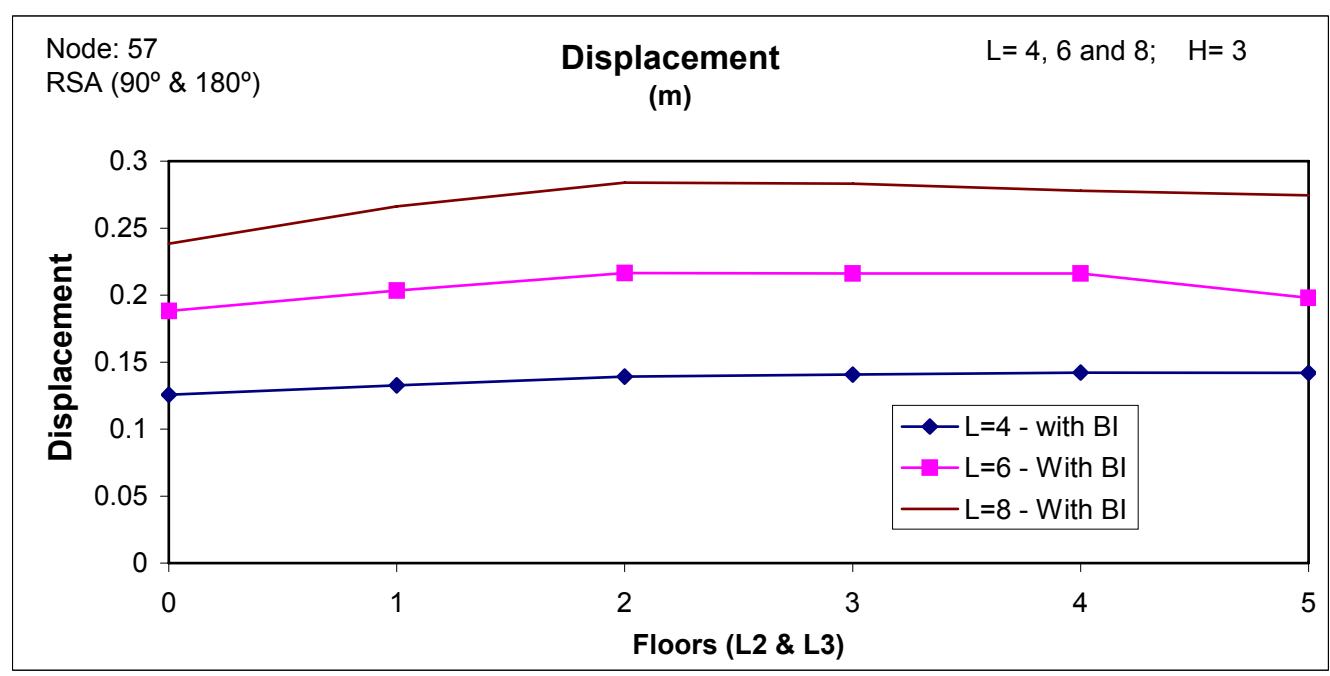

Figure 16: Resultant relative displacement for asymmetric frame with BI devices $(\mathrm{H}=3 \mathrm{~m}$; parametric study for $\mathrm{L}=4,6$ and $8 \mathrm{~m})$

Figure 17 refers to the results of 30 parametric cases giving the resultant total acceleration at the reference node, for the asymmetric frame without base-isolation devices; Figure 18 refers to the results of 30 parametric cases giving the resultant total acceleration at the reference node, for the asymmetric frame with base-isolation devices. The general trend of the different curves is quite coherent with the remarks made before with respect to Figures 13-16. It is apparent from the results that the maximum decrease of total acceleration associated with the use of BI devices happens when slab floors (L2 and L3) exist up to $3^{\text {rd }}$ floor (as well as up to $4^{\text {th }}$ and $5^{\text {th }}$ floors) for inter-story height $\mathrm{H}=3 \mathrm{~m}$, for which occurs the larger difference between the resultant total acceleration without and with elastomer isolators; for an inter-story height $\mathrm{H}=4 \mathrm{~m}$, such decrease is much less noticeable. This can be viewed as a measure of efficiency of the BI device as well as of a typological optimal effect. 


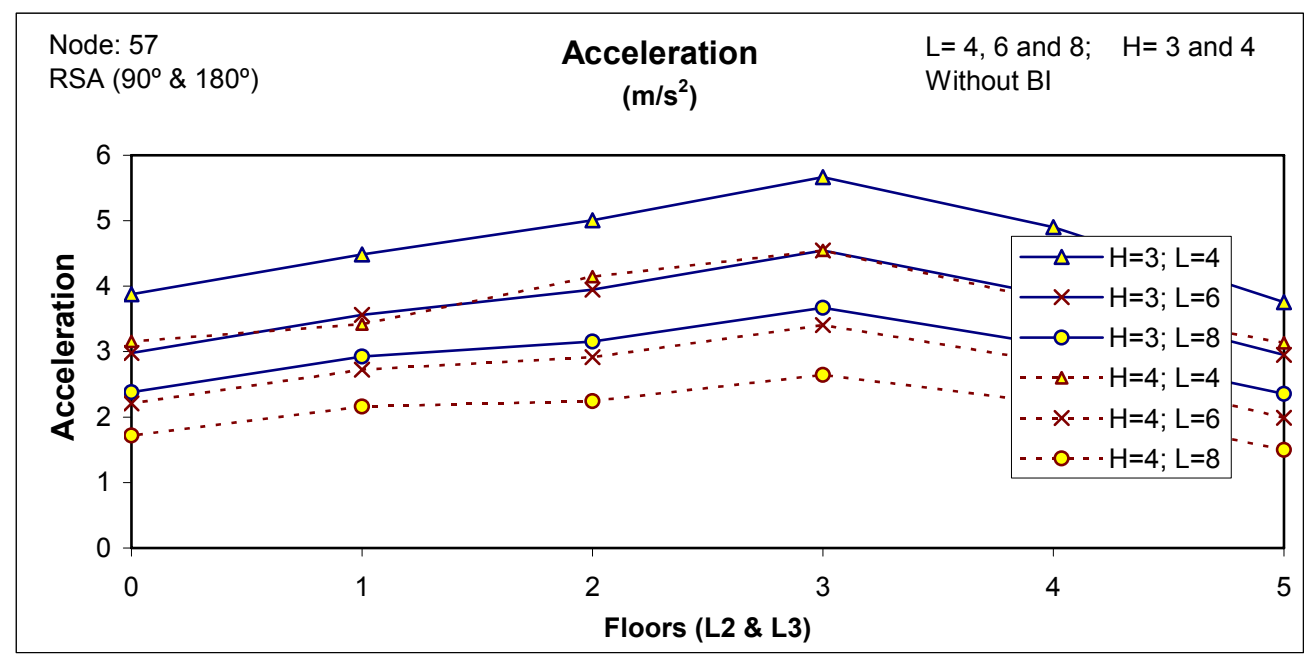

Figure 17: Resultant total acceleration for asymmetric frame without base-isolation devices $(\mathrm{H}=3 \mathrm{~m}$ and $4 \mathrm{~m}$; parametric study for $\mathrm{L}=4,6$ and $8 \mathrm{~m})$

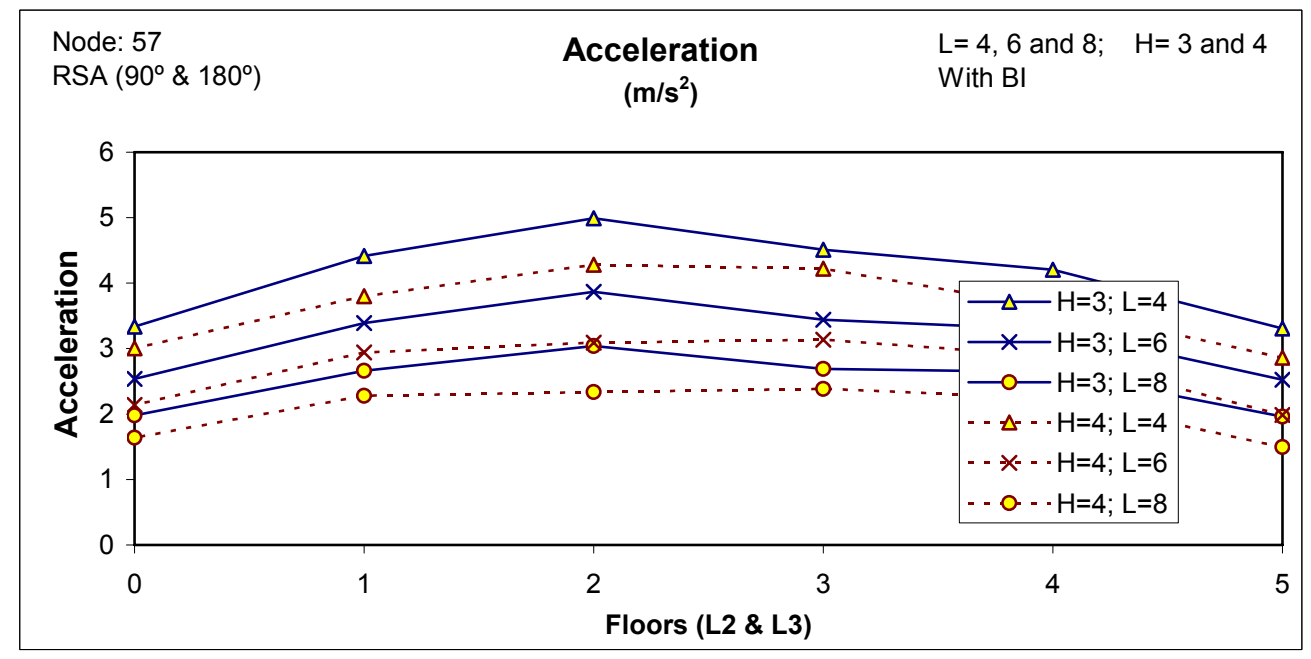

Figure 18: Resultant total acceleration for asymmetric frame with base-isolation devices $(\mathrm{H}=3 \mathrm{~m}$ and $4 \mathrm{~m}$; parametric study for $\mathrm{L}=4, \overline{6 \text { and }} 8 \mathrm{~m})$

Such typological effect is quite clear when comparing 3 pairs of curves of the parametric study (without and with $\mathrm{BI}$ devices) for the inter-story height $\mathrm{H}=4 \mathrm{~m}$, but for the 3 values of beam spans or distance between the columns of the frames along two orthogonal vertical planes (Figures 19-21).

From these figures (for inter-story height $\mathrm{H}=4 \mathrm{~m}$ ) it is noticeable the loss of efficiency (even inability) of the BI devices in reducing reference node resultant total acceleration, when the rigid slabs (L2 and L3) are only placed up to $1^{\text {st }}$ and $2^{\text {nd }}$ floors. Also no comparable reduction occurs when the rigid slabs (L2 and L3) are placed up to $4^{\text {th }}$ and $5^{\text {th }}$ floors. Only when the rigid slabs (L2 and L3) are placed up to $3^{\text {rd }}$ floor, occurs reduction of resultant total acceleration at the reference node. 


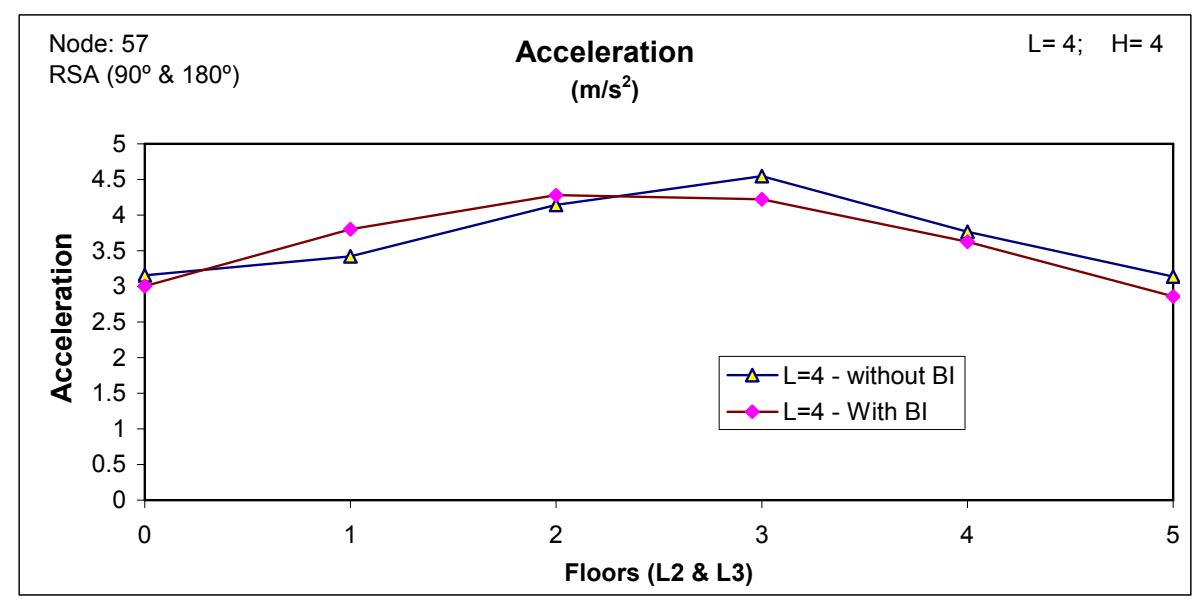

Figure 19: Resultant total acceleration for asymmetric frame without and with BI devices (parametric study for $\mathrm{H}=4 \mathrm{~m}$ and $\mathrm{L}=4 \mathrm{~m}$ )

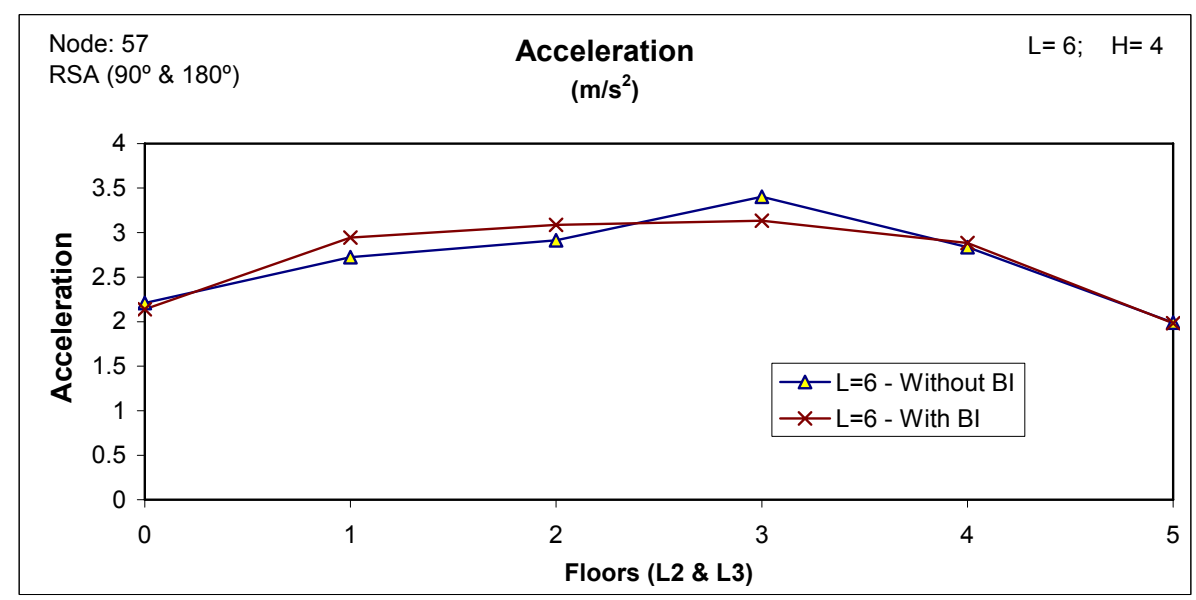

Figure 20: Resultant total acceleration for asymmetric frame without and with BI devices (parametric study for $\mathrm{H}=4 \mathrm{~m}$ and $\mathrm{L}=6 \mathrm{~m}$ )

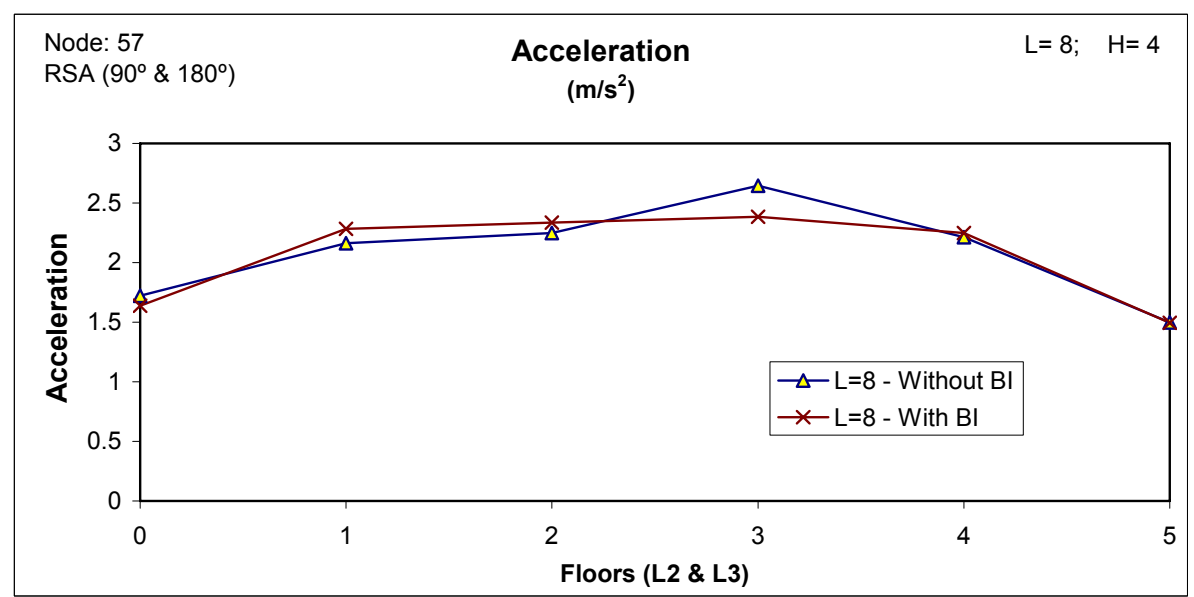

Figure 21: Resultant total acceleration for asymmetric frame without and with BI devices (parametric study for $\mathrm{H}=4 \mathrm{~m}$ and $\mathrm{L}=8 \mathrm{~m}$ ) 


\section{Conclusions}

In this study it was evident the need to study the variation of the geometry of a structural system and its typology for maximizing the performance of the system of dissipation of energy (BI devices). It was verified that the introduction of asymmetries in elevation alters significantly the behaviour of the structure seismically isolated and that the introduction of elastomer isolators introduces a new pattern for variation of such behaviour.

On the base of this study it is recommended the modelling of several 3D frames with predefined geometry (such as the one that can be use in a prefabricated system) for optimizing its performance as well as for decreasing overall costs (decreasing seismic damages). Further detailed computational studies are still needed, which should be experimentally validated whenever possible, so that the know-how and conclusions could be extended to a similar approach dealing with 'smart' base isolation systems (Ramallo et al. [14]).

\section{Acknowledgements}

This research was partially developed within the scientific and technical framework of the Research Project COVICOCEPAD, approved under Program Eurocores from the European Science Foundation (ESF). The sponsoring of the research project by Fundação para a Ciência e a Tecnologia FCT (Lisbon - Portugal) as well as from ESF (Strasbourg), is here acknowledged and thanked.

\section{References}

[1] Barros, RC and Cesar, MB, "A Parametric Study on the Seismic Behaviour of an Asymmetric Three-Dimensional Steel Frame with Base Isolation Devices", CONVIB Network Final Meeting, Santorini - Greece (June $30^{\text {th }}-$-July $1^{\text {st }} 2005$ ), CD of Final Presentations and Conclusions, Ed.: L Faravelli and F Casciatti, University of Pavia, Italy, 2006.

[2] RSA, "Regulamento de Segurança e Acções para Estruturas de Edifícios e Pontes", Decreto-Lei no 235/83, INCM (Imprensa Nacional Casa da Moeda), Lisbon, Portugal, 1983.

[3] Barros RC and Cesar MB, "Non-Linear Carrying Capacity of Asymmetric Three-Dimensional Braced Steel Frames", Proceedings of The Seventh International Conference on Computational Structures Technology (Lisbon Portugal, Sept 2004), Eds.: B. Topping and C. Mota Soares, Paper 145 (16 pages), Civil-Comp Press, Scotland, U.K., 2004.

[4] César MB, Estudos Paramétricos sobre a Instabilidade de Pórticos Metálicos Bidimensionais e Tridimensionais, Tese de Mestrado em Estruturas de Engenharia Civil (Adviser: Prof. R.C. Barros), Department of Civil Engineering, FEUP (Faculdade de Engenharia da Universidade do Porto), Porto, Portugal, 2005. 
[5] Braz Cesar M and Carneiro Barros R, "Modelação de Ligações em Pórticos Associada a Estudo Paramétrico do Comportamento Não Linear Geométrico de Pórticos Metálicos Tridimensionais Assimétricos", Métodos Numéricos en Ingeniería 2005; Eds.: JL Perez Aparício, A Rodiguez Ferran, JA Câncio Martins, R Gallego, J César de Sá; Area: Estabilidad y Análisis No Lineal de Estructuras Metálicas - Paper a420 (20 pages), SEMNI, Spain, 2005.

[6] César MB and Barros RC, "Parametric Study of the Non-Linear Geometric Behaviour and Carrying Capacity of 3D Asymmetric Steel Frames", Civil Engineering Computing, Ed.: BHV Topping, Paper 155, 17 pages, Civil-Comp Press, Scotland, U.K., 2005 (submitted to Computers \& Structures).

[7] SAP, "SAP 2000 Software Verification", Computers and Structures Inc., Berkeley, California, USA, 2003.

[8] Naeim F and Kelly JM, Design of Seismic Isolated Structures: from theory to practice, John Wiley and Sons, New York, USA, 1999.

[9] Soong TT and Dargush GF, Passive Energy Dissipation Systems in Structural Engineering, $2^{\text {nd }}$ edition, John Wiley \& Sons Ltd., Chichester, West Sussex, England, 1999.

[10] Alhan C and Gavin H, "Parametric Analysis of Passive Damping in Base Isolation", 16th ASCE Engineering Mechanics Conference (July 16-18, 2003), University of Washington, Seattle, USA, 2003.

[11] Osinski Z (editor), Damping of Vibrations, A.A. Balkema Publishers, Rotterdam, Netherlands, 1998.

[12] CEN, Structural bearings, pr EN 1337 (Final draft of January 2003), European Committee for Standardization (CEN), Brussels, Belgium, 2003.

[13] SETRA, "Appareils d'appui en caoutchouc fretté: Utilisation sur les ponts, viaducs et structures similaires - Guide technique", Service d'Études Techniques des Routes et Autoroutes (SETRA), ref. 0032, France, 2000.

[14] Ramallo JC, Johnson EA and Spencer BF, "Smart Base Isolation Systems", Journal of Engineering Mechanics, Vol. 128, No. 10, October 2002, pp. 10881100, ASCE, New York, USA, 2002. 